\title{
PENGARUH PENDIDIKAN KESEHATAN TERHADAP UPAYA PENCEGAHAN HIPOGLIKEMIA PADA PASIEN DIABETES MELLITUS DI RUANG INTENSIVE RSUD DR. MOEWARDI SURAKARTA TAHUN 2016
}

\author{
Arnis Prilli Dharmastuti, Dwi Ariani Sulistyowati \\ Kementerian Kesehatan Politeknik Kesehatan Surakarta Jurusan Keperawatan
}

\begin{abstract}
Hypoglycemia, Health Education, Knowledge, Patient. Hypoglycemia is one of the complications faced by people with diabetes mellitus, ie blood glucose levels fall below 50 to $60 \mathrm{mg} / \mathrm{dl}$. Hypoglycemia may occur acutely, suddenly and can be life-threatening. Management of diabetes mellitus one of them is health education, especially about complications, namely Hypoglycemia. The objectives of this study were 1) to identify the level of knowledge of diabetes mellitus patients about prevention of hypoglycemia prior to health education 2) to identify the knowledge level of diabetes mellitus patients about hypoglycemia prevention after health education 3) to analyze knowledge change about prevention of hypoglycemia in patients with diabetes mellitus before and after the provision of health education in the intensive space of Dr Moewardi Hospital in 2016. This research type is experimental with pre-experimental design, variable approach using pre and post test designs method and data analysis used is Paired T-Test. The result of this research is there is influence of health education toward prevention effort of hypoglycemia in patient of diabetes mellitus in intensive room of Dr Moewardi Hospital 2016. This is proved by Paired T-Test test analysis on the value of knowledge before and after given health education obtained $t$ count $=$ $-19,090$, whereas $t$ table value 2,042 so value $-t$ arithmetic $<-t$ table $(-19,090<-$ 2,042) and sig. $0.000(<0.05)$ then Ho is rejected and Ha accepted, meaning there is a significant difference between the value of knowledge before and after being given health education about hypoglycemia. There is an influence of health education on prevention of hypoglycemia in people with diabetes mellitus in intensive space Dr Moewardi Hospital in 2016.
\end{abstract}

Keywords: Hypoglycemia, Health Education, Knowledge, Patient

\begin{abstract}
Abstrak : Hipoglikemia, Pendidikan Kesehatan, Pengetahuan, Pasien. Hipoglikemia adalah salah satu komplikasi yang dihadapi oleh penderita diabetes mellitus, yaitu kadar glukosa darah turun dibawah 50 hingga $60 \mathrm{mg} / \mathrm{dl}$. Hipoglikemia dapat terjadi secara akut, tiba - tiba dan dapat mengancam nyawa. Penatalaksanaan diabetes mellitus salah satunya adalah pendidikan kesehatan terutama tentang komplikasi, yaitu Hipoglikemia. Tujuan penelitian ini adalah 1) mengidentifikasi tingkat pengetahuan pasien diabetes mellitus tentang upaya pencegahan hipoglikemia sebelum diberikan pendidikan kesehatan 2) mengidentifikasi tingkat pengetahuan pasien diabetes mellitus tentang upaya pencegahan hipoglikemia sesudah diberikan pendidikan kesehatan 3) menganalisis perubahan pengetahuan tentang upaya pencegahan hipoglikemia pada pasien diabetes mellitus sebelum dan sesudah pemberian pendidikan
\end{abstract}


kesehatan di ruang intensive RSUD Dr Moewardi tahun 2016. Jenis penelitian ini adalah eksperimental dengan desain pra-eksperimental, pendekatan variable menggunakan metode pre and post test designs dan analisis data yang digunakan adalah dengan uji Paired T-Test. Hasil penelitian ini adalah ada pengaruh pendidikan kesehatan terhadap upaya pencegahan hipoglikemia pada penderita diabetes mellitus di ruang intensive RSUD Dr Moewardi tahun 2016. Hal ini dibuktikan dengan uji analisis Uji Paired T-Test pada nilai pengetahuan sebelum dan sesudah diberikan pendidikan kesehatan didapatkan hasil t hitung $=-19,090$, sedangkan t tabel nilai 2,042 jadi nilai $-t$ hitung $<-t$ tabel $(-19,090<-2,042)$ dan sig. 0,000 $(<0,05)$ maka Ho ditolak dan Ha diterima, artinya ada perbedaan yang signifikan antara nilai pengetahuan sebelum dan sesudah diberikan penyuluhan kesehatan tentang hipoglikemia. Ada pengaruh pendidikan kesehatan terhadap upaya pencegahan hipoglikemia pada penderita diabetes mellitus di ruang intensive RSUD Dr Moewardi tahun 2016.

\section{Kata Kunci : Hipoglikemia, Pendidikan Kesehatan, Pengetahuan, Pasien}

\section{PENDAHULUAN}

Hipoglikemia adalah salah satu komplikasi yang dihadapi oleh penderita diabetes mellitus. Tidak seperti nefropati diabetik ataupun retinopati diabetik yang berlangsung secara kronis, hipoglikemia dapat terjadi secara akut, tiba - tiba dan dapat mengancam nyawa. Hal tersebut disebabkan karena glukosa adalah satu - satunya sumber energi otak dan hanya dapat diperoleh dari sirkulasi darah karena jaringan otak tidak memiliki cadangan glukosa. Kadar gula darah yang rendah pada kondisi hipoglikemia dapat menyebabkan kerusakan sel - sel otak. Kondisi inilah yang menyebabkan hipoglikemia memiliki efek yang fatal bagi penyandang diabetes melitus, di mana $2 \%-4 \%$ kematian penderita diabetes melitus disebabkan oleh hipoglikemia (PERKENI,2011). Sedangkan The Diabetes Control and Complication Trial (DCCT) melaporkan diperkirakan $2-4 \%$ kematian orang dengan diabetes tipe 1 berkaitan dengan hipoglikemia. Hipoglikemia juga umum terjadi pada penderita diabetes tipe 2 , dengan tingkat prevalensi $70-80 \%$ (Riskesdas, 2013).

World Health Organisation

(WHO) menyatakan bahwa Indonesia menempati urutan ke empat terbesar di dunia dalam jumlah penderita diabetes, tahun 2000 terdapat 5,6 juta penderita \& tahun 2006 menjadi 14 juta \& 21 juta jiwa tahun 2025. Diantara provinsi yang ada di Indonesia, jawa tengah memiliki prevalensi diabetes yang cukup tinggi. Menurut Kemenkes (2011) prevalensi diabetes melitus tergantung insulin di Provinsi Jawa Tengah pada tahun 2011 sebesar $0,09 \%$, mengalami peningkatan bila dibandingkan prevalensi tahun 2010 sebesar $0,08 \%$. Jumlah penderita hipoglikemia pada diabetes di Indonesia senada dengan prevalensi diabetes di Indonesia yaitu $1,1 \%$ secara nasional dan $5,7 \%$ pada penduduk perkotaan di Indonesia. Prevalensi diabetes tersebut berbeda - beda diberbagai provinsi dan prevalensi diabetes di daerah perkotaan di Jawa Tengah sebesar 7,8\% (Dinkes Jateng, 2011). Jumlah penderita hipoglikemia sebesar 31 pasien dari 1169 pasien 
penderita diabetes mellitus di Rumah Sakit Umum Daerah (RSUD) Dr. Moewardi tahun 2015 dari bulan Januari sampai dengan bulan Juni.

Upaya pengelolaan DM yang lebih baik, terencana, dan berkelanjutan harus dilaksanakan berdasarkan 4 pilar utama pengelolaan DM, yaitu perencanaan makan, latihan jasmani, obat berkhasiat hipoglikemik, dan penyuluhan kesehatan (Weiss at.al., 2006). Prevalensi Diabetes melitus yang meningkat, secara tidak langsung akan meningkatkan angka kesakitan dan kematian akibat Diabetes Mellitus dan komplikasinya. Pengetahuan dan perilaku penderita Diabetes Mellitus berperan dalam mengurangi terjadinya komplikasi. Penelitian yang dilakukan oleh Rina Ambarwati tahun 2009, didapatkan adanya hubungan antara pengetahuan tentang penyakit dengan motivasi dalam mencegah terjadinya komplikasi pada penderita Diabetes Mellitus di Puskesmas Kartasura. Penelitian lain yang dilakukan oleh Jazilah, Paulus dan Toto mendapatkan adanya hubungan yang signifikan antara pengetahuan, sikap dan praktik penderita Diabetes Mellitus mengenai pengelolaan Diabetes Mellitus dengan kendali kadar gula darah.

Diabetes Mellitus dapat diminimalkan dan dicegah dengan Pemberian Penyuluhan Kesehatan, karena itu akan sangat efektif untuk mencegah terjadinya komplikasi Diabetes Mellitus. Mengubah dan membentuk suatu perilaku tidaklah mudah. Ketika seseorang akan mengadopsi suatu perilaku maka terlebih dahulu dia harus tahu apa arti dan manfaat perilaku tersebut bagi dirinya, maka akan terbentuk suatu perubahan perilaku dari yang tidak baik menjadi lebih baik. Pemberian pendidikan kesehatan yang baik dan tepat dapat meningkatkan kesadaran penderita DM untuk mau mengubah perilaku dalam menjalani program pengobatan yang diberikan sehingga kadar gula dapat dikendalikan dan mencegah berbagai komplikasi akut khususnya komplikasi hipoglikemia. Penderita DM yang tidak mendapatkan promosi kesehatan memiliki resiko empat kali lebih tinggi terkena komplikasi dibanding dengan penderita DM yang mendapat pendidikan kesehatan.

Berdasarkan latar belakang dan data di atas, maka penulis tertarik untuk meneliti bagaimana "Pengaruh pendidikan kesehatan terhadap upaya pencegahan hipoglikemia pada pasien Diabetes Mellitus di Ruang Intensive RSUD Dr. Moewardi Surakarta."

\section{METODE PENELITIAN}

Jenis penelitian ini adalah eksperimental dengan desain praeksperimental, pendekatan variable menggunakan metode pre and post test designs dan analisis data yang digunakan adalah dengan uji Paired TTest. Populasi dalam penelitian ini adalah pasien diabetes melitus yang dirawat di ruang Intensif RSUD Dr. Moewardi, sampel yang dipilih dalam penelitian ini adalah total sampling. Jumlah sampel yang diambil adalah semua pasien Diabetes Mellitus yang berada di Ruang Intensive Care Unit dan High Care Unit Interna RSUD Dr. Moewardi Surakarta, dengan jumlah 32 responden dalam rentang waktu 2 bulan responden digunakan semua.

\section{HASIL PENELITIAN}

1. Nilai Sebelum Pendidikan Kesehatan 
Tabel 1

Distribusi Frekuensi Nilai

Pengetahuan Sebelum Penkes

\begin{tabular}{ccc}
\hline Nilai & Jumlah & Persentase \\
\hline Baik & 0 & 0 \\
Cukup & 11 & 34,4 \\
Kurang & 21 & 56,6 \\
\hline Total & 32 & 100 \\
\hline Pada & hasil & diatas dari 32
\end{tabular}

responden yang diteliti didapatkan data responden paling banyak dengan nilai kurang sejumlah 21 responden $(56,6 \%)$. Responden dengan nilai cukup ada $11(34,4 \%)$.

2. Nilai Sesudah Pendidikan Kesehatan

Tabel 2

Distribusi Frekuensi Nilai

Pengetahuan Sesudah Penkes

\begin{tabular}{|c|c|c|}
\hline Nilai & Jumlah & Persentase \\
\hline Baik & 30 & 93,8 \\
\hline Cukup & 2 & 6,3 \\
\hline Kurang & 0 & 0 \\
\hline Total & 32 & 100 \\
\hline
\end{tabular}

responden yang diteliti didapatkan data responden paling banyak dengan nilai baik sejumlah 30 responden $(93,8 \%)$. Sedangkan responden dengan nilai cukup ada $2(6,3 \%)$.

\section{Deskripsi Data}

\section{Tabel 3}

Distribusi Responden Sebelum Dan Sesudah Penyuluhan Kesehatan

\begin{tabular}{llll}
\hline Variabel & $\begin{array}{l}\text { Rata- } \\
\text { rata }\end{array}$ & $\begin{array}{l}\text { Juml } \\
\text { ah }\end{array}$ & $\begin{array}{l}\text { Std. } \\
\text { Deviatio } \\
\mathrm{n}\end{array}$ \\
\hline $\begin{array}{l}\text { Nilai } \\
\text { sebelum } \\
\text { penkes }\end{array}$ & 55,63 & 32 & 5.351 \\
$\begin{array}{l}\text { Nilai } \\
\text { sesudah } \\
\text { penkes }\end{array}$ & 86,25 & 32 & 7.513 \\
\hline \multicolumn{1}{r}{ Pada } & hasil & diatas & diketahui
\end{tabular}

bahwa nilai sebelum penkes dari ratarata 32 responden adalah 55,63 dengan standar deviasi 5,351. Sedangkan pada rata-rata nilai sesudah penkes dari 32 responden adalah 86,25 dengan standar deviasi 7,513. Dari hasil tersebut dapat disimpulkan ada peningkatan nilai ratarata tingkat pengetahuan responden sebesar 30,62. Pengetahuan responden sebelum diberikan penkes rendah dan banyak yang mengalami hipoglikemia sehingga mereka tertarik dan minat untuk diberikan penkes, sehingga diperoleh hasil nilai sesudah penkes baik. Menurut Azwar (2009) Minat sebagai suatu kecenderungan atau keinginan yang tinggi terhadap sesuatu dengan adanya pengetahuan yang tinggi didukung minat yang cukup dari seseorang sangatlah mungkin seseorang tersebut akan berperilaku sesuai dengan apa yang diharapkan. Sehingga dengan minat yang tinggi maka akan didapatkan kenaikan nilai pengetahuan pada responden. Menurut Smeltzer dan Bare (2002) ada 5 komponen dalam penatalaksanaan DM yaitu : Diit, Latihan jasmani, Pemantauan, Terapi (jika diperlukan) dan Pendidikan. Komplikasi akut pada diabetes melitus yang penting dan berhubungan dengan keseimbangan kadar glukosa darah dalam jangka pendek salah satunya adalah Hipoglikemia, terjadi kalau kadar glukosa darah turun dibawah 50 hingga $60 \mathrm{mg} / \mathrm{dl}$. Keadaan ini dapat terjadi akibat pemberian preparat insulin atau preparat oral yang berlebihan, konsumsi makanan yang terlalu sedikit. Menurut Notoatmodjo (2007), Pendidikan kesehatan adalah suatu kegiatan atau usaha untuk menyampaikan pesan kesehatan kepada masyarakat, kelompok atau individu dengan harapan dapat memperoleh pengetahuan tentang kesehatan yang lebih baik. 


\section{PEMBAHASAN}

Hasil penelitian tersebut sesuai dengan teori bahwa salah satu penatalaksanaan DM adalah pendidikan kesehatan terutama tentang komplikasi DM, yaitu salah satunya adalah Hipoglikemia. Pendidikan kesehatan ini sangatlah bagus untuk meningkatkan pengetahuan pasien diabetes mellitus. Pendidikan kesehatan merupakan suatu bentuk tindakan mandiri keperawatan untuk membantu klien baik individu, kelompok, maupun masyarakat dalam mengatasi masalah kesehatannya melalui kegiatan pembelajaran, yang didalamnya perawat berperan sebagai perawat pendidik. Adapun tujuan yang diperoleh setelah dilakukan penyuluhan kesehatan untuk meningkatkan status kesehatan, mencegah timbul komplikasi salah satunya hipoglikemia, mempertahankan derajat kesehatan yang sudah ada, memaksimalkan fungsi dan peran pasien selama sakit, serta membantu pasien dan keluarga untuk mengatasi masalah kesehatan khususnya tentang hipoglikemia, baik penanganan atau pencegahan.

4. Uji Paired T-Test

Tabel 4

Uji Paired T-Test

\begin{tabular}{cccc}
\hline Pair 1 & $\mathrm{t}$ & $\mathrm{df}$ & Sig. \\
\hline $\begin{array}{c}\text { Nilai } \\
\text { sebelum- } \\
\text { sesudah } \\
\text { penkes }\end{array}$ & $-16,952$ & 31 & $0,0 ` 00$ \\
& & &
\end{tabular}

Pada hasil diatas diketahui nilai $\mathrm{t}$ hitung $=-16,956$ sedangkan $\mathrm{t}$ tabel dengan df 32 dengan taraf signifikansi 0,05 didapatkan nilai 2,042. Dikarenakan nilai -t hitung < -t tabel ($16,956<-2,042)$ dan sig. $0,000(<0,05)$ maka Ho ditolak, artinya ada perbedaan yang signifikan antara nilai pengetahuan sebelum dan sesudah diberikan penyuluhan kesehatan tentang hipoglikemia, jadi terdapat pengaruh peningkatan nilai pengetahuan pada pasien Diabetes Mellitus di ruang intensif RSUD Dr. Moewardi Surakarta.

\section{KESIMPULAN DAN SARAN KESIMPULAN}

1. Tingkat pengetahuan tentang hipoglikemia sebelum diberikan penkes sebagian besar adalah pengetahuan dengan nilai kurang sejumlah 21 responden $(56,6 \%)$ dari 32 responden pada penderita diabetes mellitus di ruang intensive RSUD Dr Moewardi tahun 2016.

2. Tingkat pengetahuan tentang hipoglikemia sesudah diberikan penkes sebagian besar adalah pengetahuan dengan nilai baik sejumlah 30 responden $(93,8 \%)$ dari 32 responden pada penderita diabetes mellitus di ruang intensive RSUD Dr Moewardi tahun 2016.

3. Terdapat perbedaan signifikansi sebelum dan sesudah diberikan penyuluhan kesehatan tentang hipoglikemia, maka dapat disimpulkan bahwa ada pengaruh pendidikan kesehatan terhadap upaya pencegahan hipoglikemia pada penderita diabetes mellitus di ruang intensive RSUD Dr Moewardi tahun 2016.

\section{SARAN}

1. Bagi Pasien

Penyuluhan kesehatan tentang hipoglikemia dapat dijadikan sebagai infomasi dan preventif bagi pasien diabetes mellitus 
terutama untuk meningkatkan status kesehatan, mencegah timbul komplikasi salah satunya hipoglikemia, mempertahankan derajat kesehatan yang sudah ada, memaksimalkan fungsi dan peran pasien selama sakit, serta membantu pasien dan keluarga untuk mengatasi masalah kesehatan khususnya tentang hipoglikemia, baik penanganan atau pencegahan.

2. Bagi Tenaga Kesehatan RSUD Dr. Moewardi

Diharapkan dengan penelitian ini mampu menambah pengetahuan perawat dan mengidentifikasi pasien yang beresiko tinggi terjadi hipoglikemia, perawat harus mengidentifikasi tentang pola hidup, pola makan, obat diabetes yang dapat memicu terjadinya hipoglikemia dan memotivasi pasien untuk rutin mengontrol kadar gula darah. Perawat harus melakukan pendidikan kesehatan pada pasien diabetes mellitus mengenai hipoglikemia.

3. Bagi Peneliti Selanjutnya
a. Penelitian selanjutnya diharapkan dilakukan dengan waktu dan responden yang lebih, sehingga kemaknaan penelitian lebih besar.
b. Penelitian selanjutnya diharapkan melakukan penelitian yang lebih spesifik, dengan memperhatikan factor variable pengganggu dan lebih memperhatikan factor yang bisa membuat bias hasil penelitian, seperti tingkat pendidikan, status hipoglikemia, minat responden dan kemungkinan

responden mencari sumber literature lain.

\section{DAFTAR RUJUKAN}

Arikunto, S. (2010). Prosedur Penelitian. Jakarta: Rineka Cipta

Arisman. (2010). Buku Ajar Ilmu Gizi: Obesitas, Diabetes Mellitus, dan Dislipidemia. Jakarta: EGC

Azwar, S. (2003). Sikap Manusia Teori dan Pengukurannya. Yogyakarta: Pustaka Pelajar.

Baughman, D., \& Joann, C. (2000). Keperawatan Medikal Bedah. Jakarta: EGC

Corwin, E.J. (2009). Buku Saku Patofisiologi. Jakarta: EGC.

Dewi, P., \& Anugraheni, K. (2008). Faktor-faktor yang Mempengaruhi Praktek Pengukuran Makanan (Diet) Sehari-hari pada Pasien DM tipe 2. Jurnal Epidemiologi. Tidak dipublikasikan.

Ernawati. (2012). Kemampuan Melakukan Penatalaksanaan Hipoglikemia Berdasarkan Karakteristik dan Pengetahuan Pasien Diabetes Mellitus. Jurnal kesehatan Program Ilmu Keperawatan Universitas Islam Negeri Syarif Hidayatullah.

Farida, Arham \& Sukriyadi. (2013). Hubungan Antara Pengetahuan Sikap dan Tindakan Pasien Diabetes Melitus dengan Pencegahan Komplikasi Hipoglikemia di RSUD Labuang Baji Makasar tahun 2013. Jurnal kesehatan e-library Stikes Nani Hasanudin Makasar.

Guntur, H.A., Arifin, \& Diding. (2010). Protap Pelaksanaan Kegawatan HCU-Interna: $\mathrm{HCU}$ 
Bedah RS.Dr.Moewardi, Surakarta. UPT Penerbitan dan Percetakan UNS.

Hidayat, A. (2009). Metode Penelitian Kebidanan dan Teknik Analisa Data. Jakarta: Salemba Medika.

Hidayat, A. (2014). Metode Penelitian Kebidanan dan Teknik Analisa Data (Edisi 2). Jakarta: Salemba Medika.

Kemenkes RI. (2011). Profil Kesehatan Indonesia 2009 dan 2010. Jakarta: Kemenkes RI.

Machfoedz, I., Eko, S., Sutrisno., Sabar, W.I. (2005). Pendidikan Kesehatan Bagian dari Promosi Kesehatan. Yogyakarta: Fitramaya.

Notoatmojo. (2003). Pendidikan dan Perilaku Kesehatan. Jakarta : Rineka Cipta.

Notoatmojo. (2005). Metodelogi Penelitian Kesehatan. Jakarta: PT. Rineka Cipta.

Notoatmojo. (2007). Pendidikan dan Perilaku Kesehatan (Edisi 2). Jakarta: PT. Rineka Cipta.

Notoatmojo. (2009). Metodelogi Penelitian Kesehatan (Edisi 2). Jakarta: PT. Rineka Cipta

Nursalam. (2008). Konsep dan Penerapan Metodologi Penelitian Ilmu Keperawatan. Jakarta: Salemba Medika.

Nursalam. (2009). Konsep dan penerapan metodologi penelitian ilmu keperawatan (edisi 2). Jakarta: Salemba Medika.

Perkumpulan Endokrin Indonesia. (2011). Konsensus Pengelolaan dan Pencegahan Diabetes Mellitus Tipe 2 di Indonesia 2011 Cetakan ke 4. Jakarta: PB PERKENI
Price, S.A \& Wilson, L.M. (2006). Patofisiologi Konsep Klinis Proses Proses Penyakit. Edisi 6. Jakarta : EGC.

Profil Dinas Kesehatan Jawa Tengah. (2011).

http://www.depkes.go.id /profil_kes_provinsi_2011/13, diperoleh tanggal 9 Januari 2016.

Riset Kesehatan Dasar (Riskesdas). (2013).

http://depkes.go.id/riskesdas201 $\underline{3}$, diperoleh tanggal 9 Januari 2016.

Riwidikdo, Handoko. (2010). Statistik Kesehatan. Yogyakarta: Mitra Cendikia.

Sastroasmoro, S., \& Ismael, S. (2006). Dasar - Dasar Metodologi Penelitian Klinis Edisi 2. Jakarta: Sagung Seto.

Setyawati, R. (2000). Beberapa Faktor yang Berhubungan dengan Keteraturan Pemeriksaan Kadar Gula Darah pada Penderita Diabetes Mellitus di Rumah Sakit Umum Kota Semarang. Diperoleh dari www.fkm.undip.ac.id, diperoleh tanggal 10 Februari 2016.

Setyohadi. (2012). Hipoglikemia dan Hiperglikemia, dalam EIMED PAPDI. Jakarta: Interna Publishing. Smeltzer Suzanne C. dan Bare Brenda G. (2002). Buku Ajar Keperawatan Medikal - Bedah Brunner \& Suddarth. Jakarta : EGC.

Sugiyono. (2009). Metode Penelitian Administrasi. Bandung: Alfabeta.

Timby, B.K., Scherer, J.C., \& Smith, N.E. (2009). Medical Surgical Nursing: Introductory $\left(7^{\text {th }}\right.$ 
8 Jurnal Keperawatan Global, Volume 2, No1, Juni 2017 hlm 1-61

Edition). Philadelphia: Lippincott.

WHO. (2012). Penanganan Diabetes Mellitus di Rumah Sakit Kecil Negara Berkembang. Jakarta: EGC

Weiss, et.al. (2006). Improvements In Glucose Tolerance And Insulin
Action Induced By Increasing Energy Expenditure $\mathrm{Or}$ Decreasing Energy Intake: A Randomized Controlled Trial. American Society for Clinical Nutrition. 